\title{
Researchers criticize NIH response to PETA claims
}

\section{- Agency closed laboratory within a day - Investigation finds only "minor problems"}

\section{Washington}

RESEARCHERS at the US National Institutes of Health (NIH) are up in arms about an incident last fall in which the agency suspended the experimental protocols of a laboratory less than 24 hours after receiving what later turned out to be a largely unsubstantiated complaint by animal activists.

Last week, a subcommittee of the NIH Animal Care and Use Committee finished a four-month investigation of the case. In the subcommittee's report, which has not yet been released, the investigators are said to have found some violations of record keeping and procedural rules within the laboratory. But the report finds no reason to suspend the experimental protocols. The protocols were reinstated in late December.

NIH officials are now reviewing their handling of the case. And the agency has set up a special committee to help it make better decisions the next time an allegation is raised.

The laboratory in question is run by Josef Rauschecker, a German brain researcher now with the National Institute of Mental Health (NIMH). In December 1989, he and three graduate students from the Max Plank Institute for Biological Cybernetics in Tübingen came to NIH's Poolesville, Maryland, facility with 48 cats, many of which had been surgically blinded and implanted with electrodes. Rauschecker is investigating neural plasticity, the ability of the brain to reorganize itself after an injury.

The conditions of the animals caused "some consternation" when they arrived, says John Miller, director of the animal welfare division in the NIH Office of Protection from Research Risks (OPRR), because of their previous surgery and a respiratory infection that many had developed during travel. The cats were inadvertently allowed to breed during quarantine, and most of the kittens died. Many of the cats also tested positive for antibodies to feline infectious peritonitis (FIP), a virus that is usually fatal. Mortality rates were relatively high, Rauschecker says, averaging about 30 per cent for kittens and 10 per cent for adults, and peaking during a one-month period in August 1991 when there was no veterinarian at Poolesville.

Staff at the facility are said to have been concerned about an unusually high mortality rate during certain experiments and the fact that Rauschecker had not obtained a breeding permit. Eventually one of them called People for the Ethical Treatment of Animals (PETA).

On 14 November, PETA faxed a complaint to Bernadine Healy, the NIH director, recounting the allegations of abuses in Rauschecker's laboratory. Mary Beth Sweetland, a PETA investigator, wrote that the employee had said that all the cats were infected with FIP on arrival, and had been allowed to live only so that Rauschecker could continue his experiments. (According to the NIH investiga-

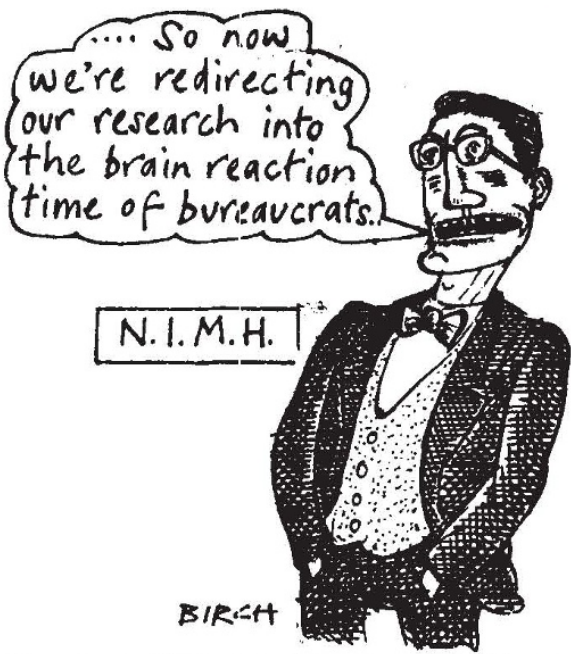

tors, most of the cats do not appear to have actually been carrying FIP, although they may have been exposed to the disease at some point.) PETA expressed its hope that Healy would give the matter her "immediate attention".

To the surprise of nearly everyone, that is exactly what happened. Within hours of receiving the fax, Healy had directed Steven Paul, director of the NIMH intramural programme, and Robert Whitney, director of the animal care committee, to investigate the matter. By the next day, she had called in the OPRR as well, "to accelerate the review", according to a response to PETA on 15 November.

Even PETA was flabbergasted by the response. "It almost made me suspicious that someone had known beforehand" about problems with Rauschecker's laboratory, says Sweetland. In fact, there had been a complaint from an employee about animal welfare in the laboratory, says Ronald Schoenfeld, deputy director of intramural research at NIMH. But it had concerned a veterinarian's treatment of a primate, not cats, and had been handled appropriately, he says. At NIH headquar- ters, PETA's complaints were new.

As NIH officials rushed to respond to the allegations, almost the only person they did not question was Rauschecker himself. He and several members of his laboratory were at the annual meeting of the Society for Neuroscience in New Orleans. When Rauschecker returned to his laboratory on 17 November, he learned that NIH had suspended his protocols.

But within a week, OPRR had bowed out of the case. Miller says that he found no reason to depart from the usual procedures, which involve an initial investigation by the animal care committee followed by a review by the intramural research director and only then by OPRR. A week later, NIMH officials recommended that the protocols be reinstated. But because the request had to be approved by the NIH animal care committee as well, the actual lifting of the suspensions took another three weeks. During the suspension period, laboratory researchers were forced to halt several experiments because they were not allowed to take regular readings from instruments to which the cats were connected.

NIH officials defend their initial measures as a prudent response to a potentially serious complaint. They say they could not at first decide whether the PETA complaint had merit because Rauschecker was not available and Poolesville is several miles from the main NIH campus. "If it had been someone in a facility next door who we could walk down to and check on," says NIH's Schoenfeld, "the response might have been different".

But some NIH researchers see it differently. They are concerned that NIH overreacted to the complaint to avoid a potential public relations disaster. "I was very disturbed when $I$ heard that allegations from a animal rights organization had resulted in a protocol being suspended," says Frederick Miles, an animal care committee member. "PETA's in the business of shutting down research. If we're not careful, the [interests of the] scientist will be left out of this entirely."

PETA's letter to Healy appears to be the first complaint about intramural research to go straight to a NIH director. "It caught everyone by surprise," Miles says. "We were very unprepared." But its success makes it likely that animal rights activists will use the tactic again.

With that in mind, the NIH animal care committee has set up a subcommittee, chaired by Miles, to provide a mechanism to avoid confusion in the future. One potential solution, Miles says, is to appoint an NIH 'ombudsman' who could order a fact-finding investigation within hours of receiving an allegation. With veterinarians and other experts on call, a 'quick response team' would visit the implicated laboratory and decide within 24 hours what to do next.

Christopher Anderson 